\title{
Analyzing the Technology Trends of Smartphone in China using Patent Maps
}

\author{
Hu Yunqi \\ Antai College of \\ Economics \& Management, \\ Shanghai Jiao Tong University
}

\author{
Hu Daiping \\ Antai College of \\ Economics \& Management, \\ Shanghai Jiao Tong University
}

\begin{abstract}
This paper retrieves smartphone patent data in China and builds word frequency matrix and relation matrix of patents. After drawing the multidimensional patent maps, this paper finds out the import patents and analyzes the development trend of technology in the field of smartphone.
\end{abstract}

\section{General Terms}

Smartphone, Technology, Patent

\section{Keywords}

Smartphone, Patent Map, Word Frequency Matrix, Relation Matrix

\section{INTRODUCTION}

Smartphone utilizes mobile communication network to realize wireless calling and network accessing, furthermore, they are like a palm computer with independent operating systems, independent storage spaces, which enable users to install the applications. With the aspects of excellent operating system, free application installation and full touch screen, smartphones have been used all of the whole world. But smartphones are now facing a severe situation: the decline in innovation. According to the reports, the shipment of mobile phone consecutively declined in the past seven quarters in China. The Ministry released the fourth quarter of 2013 China mobile phone shipments of 90 million 800 thousand, compared with the third quarter of 94 million 800 thousand, down $4.3 \%$, the mobile phone industry data for the first quarter of 2014, mobile phone shipments of 100 million, down $24.7 \%$. At the same time, another worrying phenomenon is the innovation of mobile phone category, but also a significant decline in the first quarter of this year, mobile phone market 607 new models, down 9.5\%. Smartphone has formed a path dependence, product upgrades have been almost along the existing route of development, namely, the larger screen size, higher resolution, faster processor, more auditors, thinner body, a higher pixel camera, has been a long time did not see the real subversive innovation, so that consumers of the mobile phone has produced visual fatigue, not very good for sales. Based on the patent data, this paper analyzes the patent in the field of smartphone, draws patent map, finds out the important patents analyzes the development of technology trend.

Patent maps are the graphs of the patent information. They are the visual result maps of information of technology, economy, law etc. in patents processed by using a variety of statistical analysis tools, text mining software and graphics software [1, 2]. Patent maps can play a good role in the analysis of patents $[3,4]$. The study and analysis of the patent map can reveal the technology focus, development trend, which can support company to make decision in business and patent strategy [5].

\section{PATENT DATA PREPARING}

Based on the method proposed by Chao-Chan Wu and HoangJyh Leu [4] and using the patents smartphone in China, this paper analyzes the mutual influence relationship between patents, finds out some important patents with great influence on others and forecasts the technology trend of patents. It includes: patent data retrieving, patent data processing, patent map drawing and analyzing.

\subsection{Patent data retrieving}

This paper uses the patent database of the State Intellectual Property Office of the P.R.C (SIPO) to retrieve patent data. Choosing the invention name as "smartphone", the type as "invention" and the application date from time 2003/01/01 to 2013/12/31, there are 637 smartphone patents, and only 578 patents are distinct and available. The patent data have the fields of the application number, application date, the applicant, IPC number and abstract. The number of patents group by the year of patent application date is shown as table

Table 1. Yearly patent application

\begin{tabular}{|c|c|c|c|c|c|c|}
\hline Year & $\mathbf{2 0 0 3}$ & $\mathbf{2 0 0 4}$ & $\mathbf{2 0 0 5}$ & $\mathbf{2 0 0 6}$ & $\mathbf{2 0 0 7}$ & $\mathbf{2 0 0 8}$ \\
\hline Number & 2 & 1 & 4 & 8 & 6 & 15 \\
\hline Year & $\mathbf{2 0 0 9}$ & $\mathbf{2 0 1 0}$ & $\mathbf{2 0 1 1}$ & $\mathbf{2 0 1 2}$ & $\mathbf{2 0 1 3}$ & Total \\
\hline Number & 11 & 34 & 64 & 173 & 260 & 578 \\
\hline
\end{tabular}

\subsection{Patent data processing}

After searching keywords from all patent abstracts, there are 20 keywords with highest frequency occurrence, namely "system", "network", "keyboard", "memory/storage", "GPS/location", "touch/screen", "server/processor", "data/signal", "transmission/communication", "picture/ image", "Bluetooth", "communication/call", "video/audio", "shell/set ", "camera", "sensor", "other module", "power", "security/password" and "application". No.1 to No.20 respectively represent the 20 keywords, shown as table 2 .

Table 2. Keywords list

\begin{tabular}{|c|c|c|c|c|}
\hline No. & $\mathbf{1}$ & $\mathbf{2}$ & $\mathbf{3}$ & $\mathbf{4}$ \\
\hline Keywords & system & network & keyboard & $\begin{array}{c}\text { memory } \\
\text { /storage }\end{array}$ \\
\hline No. & $\mathbf{5}$ & $\mathbf{6}$ & $\mathbf{7}$ & $\mathbf{8}$ \\
\hline Keywords & GPS /location & $\begin{array}{c}\text { touch } \\
\text { /screen }\end{array}$ & $\begin{array}{c}\text { server } \\
\text { /processor }\end{array}$ & data /signal \\
\hline No. & $\mathbf{9}$ & $\mathbf{1 0}$ & $\mathbf{1 1}$ & $\mathbf{1 2}$ \\
\hline Keywords & $\begin{array}{c}\text { transmission } \\
\text { /communication }\end{array}$ & $\begin{array}{c}\text { /picture } \\
\text { image }\end{array}$ & Bluetooth & $\begin{array}{c}\text { communication } \\
\text { /call }\end{array}$ \\
\hline No. & $\mathbf{1 3}$ & $\mathbf{1 4}$ & $\mathbf{1 5}$ & $\mathbf{1 6}$ \\
\hline Keywords & video/audio & $\begin{array}{c}\text { mobile } \\
\text { case }\end{array}$ & camera & sensor \\
\hline No. & $\mathbf{1 7}$ & $\mathbf{1 8}$ & $\mathbf{1 9}$ & $\mathbf{2 0}$ \\
\hline Keywords & other module & power & $\begin{array}{c}\text { security } \\
\text { /password }\end{array}$ & application \\
\hline
\end{tabular}


The number of above keywords existed in each patent are counted, and then the number of patents are calculated group by the number of the keywords, shown as table 3 .

Table 3. Keywords number in patents

\begin{tabular}{|c|c|c|c|c|c|c|}
\hline Number of keywords & $\mathbf{1}$ & $\mathbf{2}$ & $\mathbf{3}$ & $\mathbf{4}$ & $\mathbf{5}$ & $\mathbf{6}$ \\
\hline Number of patents & 17 & 71 & 88 & 98 & 116 & 91 \\
\hline Number of keywords & $\mathbf{7}$ & $\mathbf{8}$ & $\mathbf{9}$ & $\mathbf{1 0}$ & $\mathbf{1 1}$ & Total \\
\hline Number of patents & 60 & 19 & 14 & 3 & 1 & 578 \\
\hline
\end{tabular}

In order to facilitate mapping of patents, this paper selects 100 patents from the 578 patents. First, the number of patents to be selected for each year is decided according the patent yearly percentage. Second, the patents to be selected are those patents with most keywords. For example, with the express of $100 * 260 / 578=40,40$ patents will be selected for year 2013, and then select those 40 patents with most keywords. Table 4 and table 5 show the results of selection.

Table 4. Numbers of selected patents yearly

\begin{tabular}{|c|c|c|c|c|c|c|}
\hline Year & $\mathbf{2 0 0 3}$ & $\mathbf{2 0 0 4}$ & $\mathbf{2 0 0 5}$ & $\mathbf{2 0 0 6}$ & $\mathbf{2 0 0 7}$ & $\mathbf{2 0 0 8}$ \\
\hline Patents & 1 & 1 & 1 & 2 & 2 & 3 \\
\hline Year & $\mathbf{2 0 0 9}$ & $\mathbf{2 0 1 0}$ & $\mathbf{2 0 1 1}$ & $\mathbf{2 0 1 2}$ & $\mathbf{2 0 1 3}$ & Total \\
\hline Patents & 2 & 6 & 12 & 30 & 40 & 100 \\
\hline
\end{tabular}

Table 5. Number of patents for number of keywords

\begin{tabular}{|c|c|c|c|c|c|c|}
\hline Keywords & 1 & 2 & 3 & 4 & 5 & 6 \\
\hline Patents & 3 & 12 & 15 & 17 & 21 & 15 \\
\hline Keywords & 7 & $\mathbf{8}$ & $\mathbf{9}$ & $\mathbf{1 0}$ & $\mathbf{1 1}$ & Total \\
\hline Patents & $\mathbf{1 0}$ & $\mathbf{3}$ & $\mathbf{2}$ & $\mathbf{1}$ & $\mathbf{1}$ & $\mathbf{1 0 0}$ \\
\hline
\end{tabular}

\section{PATHEN MAPS AND ANALYZING}

Based on the processed patent data, this paper establishes the frequency matrix $\mathrm{P}$, cross frequency matrix $\mathrm{PP}$, cross correlation matrix $\mathrm{CC}$, relation matrix $\mathrm{C}$, draws the patent maps and then analyzes the important patents and patent technology trend.

\subsection{Word frequency patent map}

Count the number of every keyword occurred in every patent. to build the frequency matrix $P, P=\left\{p_{i k}\right\}[100 \times 20]$, where $p_{i k}$ represents the occurrence number of No. $\mathrm{k}$ keyword appears in No. $\mathrm{i}$ patent, $\mathrm{i}=1,2, \ldots, 100$, and $\mathrm{k}=1,2, \ldots, 20.3 \mathrm{D}$ patent map of matrix $P$ is shown in figure 1.

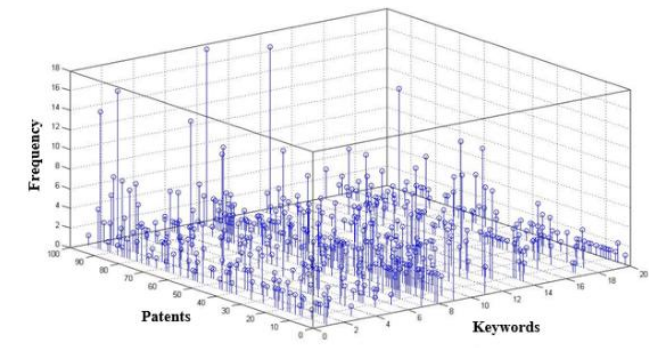

Fig 1: Word frequency patent map

The patent map of keyword frequency matrix shows that the No. 1, 2, 4, 7, 8, 9, 17, 18, which respectively represent the keyword "system", "network", "storage", "server/processor", "data/signal", "communication", "other module" and "power" have more times of occurrences and are mostly maintained in a steady state in every patents, though they occasionally have some fluctuations. No. 3, 11, 12, 15, 16, representing the "keyboard", "Bluetooth", "communication/call", "camera" and "sensor" appears less frequently, such as "keyboard" is a function module seldom used in smartphone, now mostly replaced by the touch screen. "Bluetooth", communication/call", "camera" and "sensor" in the smartphone has been thorough researched before. The left number of $5,6,10,13,14,19,20$ respectively represent the "positioning", "touch/screen", "picture/image", "video/audio", "phone case", "security/password" and "application" in the patents appears more times. They belong to the most import topic of research in the field of smartphone. According to the patent statistics of the year by year, the dynamic threedimensional patent map can also be drawn.

The numbers of occurrences of keywords No. 11, 12, 15, 16 climb up and then decline in those years. The initial increase is because the smartphone has just come out, and some of the original operation method corresponding to the phone keyboard should be changed accordingly, so research on "Bluetooth", "communication/call", "camera" and "sensor" maintains a period of growth. In the later stage, the research on them relatively reduces and goes into a bottleneck. They are not the focuses of research for competitors, so they are not the trend of technology development.

Occurrence numbers of keywords No. 5, 6, 10, 13, 14, 19, 20 are increasing year by year with an increased growth rate. These keywords are the hot research topics of smartphone. In recent years they keep in a good development state. Because of a variety of map software and social network software development. The occurrence number of keyword No. 5 representing "GPS" also grows with great speed. No. 6 representing "touch screen/screen," No. 10 representing keywords "picture/image" and No. 14 representing keyword "phone case" on condition of consumer's pursuit of more and more appearance and the sensory experience, have also been greatly developed. No. 13 representing keyword "video/audio", as the consumers pursuing more and more convenient and fast sensual pleasures, the video and audio have considerable development. No. 19 representing "security/password", its relative technology such as gesture password, digital certification and voice password have rapid development in recent years. On the occasion of network environment, No. 20 representing smartphone "application" goes up at more and more fast speed in the fields of information share and remote control. Some of the keywords of the growth speeds are still not reduced. But keyword No. 6 "screen", 10 "image", 13 "video/audio, 14 "mobile case" from 2003 to 2012 have been in the accelerated development, but they slow down obviously in the 2013. Keyword No. 5 "GPS" and 19 "security/password" in the patent cross frequency matrix statistics are in accelerating speed although the frequency of occurrence of the absolute value is not high, but the growth speed is high, according to the current development trend, they will be the widely used technology. Keyword No. 20 "application" is in a slow development speed from 2003 to 2011, but it is increases rapidly in 2012 and 2013. According to the current development trend, application of smartphone will be an import research topic in various fields associated with smartphone in the future.

\subsection{Relation matrix patent map}

The relationship between the patents can be considered as the correlation between the contents of patents. Same keyword existed in patents can be used to discover the relationship between patents. If a keyword appear in two patents, then there is a relationship between them. The greater number means more close relationship. Frequency cross matrix PP describes the relationship between the patents. Cross matrix PP can be gotten by finding the minimum numbers of 
keywords between patents from the frequency matrix $\mathrm{P}$. finding the minimum numbers. $P P=\left\{p_{i j k}\right\}[100 \times 100 \times 20], p_{i j k}$ is the number of same keyword $\mathrm{k}$ between patent $\mathrm{i}$ and patent $\mathrm{j}$. $\mathrm{p}_{\mathrm{ijk}}=\min \left\{\mathrm{p}_{\mathrm{ik}}, \mathrm{p}_{\mathrm{jk}}\right\}, \mathrm{i}, \mathrm{j}=1,2, \ldots, 100, \mathrm{k}=1,2, \ldots, 20$. The cross frequency matrix of patent maps are shown as Figure 2 (four keywords)

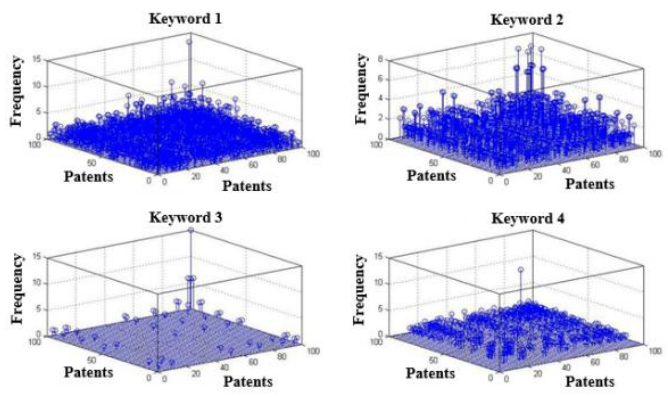

Fig 2: Cross frequency matrix patent map

Cross frequency matrix reflects the relationship of the keywords between patents and patents, the bigger the number is, the closer the relationship exists between those two patents. Defined $\mathrm{C}$ as the patent relation matrix, its component value is equal to the average value of the keyword corresponding to the cross word frequency matrix divided by the maximum number of times occurring in patents, which is a number from 0 to 1 . The relationship between matrix $C=\left\{c_{i j}\right\}[100 \times 100]$.

$$
\mathrm{c}_{\mathrm{ij}}=\sum \mathrm{p}_{\mathrm{ijk}} / \mathrm{p}_{\mathrm{k}} / \mathrm{m}
$$

where $c_{i j}$ denotes the strength of relationship between patent $i$ and patent $\mathrm{j}, \mathrm{p}_{\mathrm{k}}$ denotes the maximum number of keyword $\mathrm{k}$ appears in patents. $m$ is the size of keywords set. The patent map of the relationship matrix reflects the degree of relationship between the patent and the patent, as shown in figure 3 .

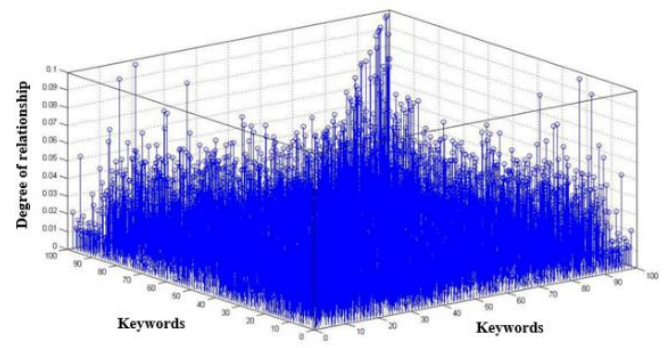

Fig 3: Relationship matrix patent map

These patents are related to the field of smartphone, some common modules are the parts of smartphone, such as the aforementioned "system", "network", "server" and "communication", so $c_{i j}$ is not 0 cannot be explained that the correlation is obvious between patent $i$ and patent $j$. This paper selects the threshold value of $t$, if $c_{i j}$ is greater than $t$, shows that there is obvious relationship between patent $i$ and patent $\mathrm{j}$, if $c_{\mathrm{ij}}$ is less than or equal to $t$ is that there is no correlation or weak correlation between patent $\mathrm{i}$ and patent $\mathrm{j}$, which will be ignored. The value of $t$ can be determined by repeated trials and minimum error. After drawing the relationship patent map of the relationship matrix with different threshold $\mathrm{t}=0.01,0.02,0.03,0.05$, this paper selects $\mathrm{t}=0.03$ as the critical value, which can not only eliminate the impact of the common modules, but also can reflect the relationship between patents. The relationship matrix patent map with $\mathrm{t}=0.03$ is shown in figure 4 .

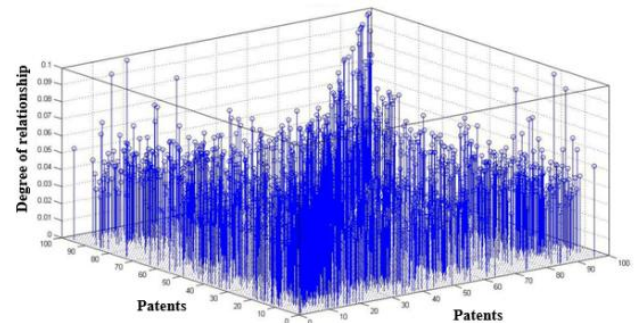

Fig 4: Relationship matrix patent map with $\mathrm{t}=\mathbf{0 . 0 3}$

The degree of relationship existed in the patent map are considered to have a significant relationship between the two patents.

\subsection{Important patents and technology trends analyzing}

After analyzing of the cross frequency matrix patent map, in the smartphone fields, "system", "network" and "server/processor", "other modules", "storage", "power", "data/information" and "communication" will be maintained in the current research state. "keyboard" and "Bluetooth", "call", "camera" and "sensor" will be reduced in research state. "touch/screen", "picture/image", "video/audio" and "phone case" will be in increasing investment state in a period of time. "GPS/location", "security/password" and "application" will be in a greatly increasing investment state. "GPS/location", "security/password" and "application" are the focuses of research in the field of smartphones in the future.

In order to evaluate the importance of the patent, this paper assigns 1 to the value of importance of two patents which have an obvious relationship between them, or assigns 0 to the value of importance. The degree of importance of a patent can be calculated by summing the value of importance between itself and other patents. The important patents can be find out with high degrees of importance. The technology involved in important patents can be considered as the key technology in the field of smartphone now. The important patents are shown as table 6 .

Table 6. Important patents

\begin{tabular}{|c|c|c|c|c|}
\hline Name & $\begin{array}{l}\text { Applicati } \\
\text { on No. }\end{array}$ & $\begin{array}{l}\text { Date of } \\
\text { Applicatio } \\
n\end{array}$ & IPC No. & Inventor \\
\hline $\begin{array}{l}\text { Extend device for } \\
\text { smartphone }\end{array}$ & $\begin{array}{l}\text { CN20121 } \\
0096090\end{array}$ & 2012.04 .01 & $\begin{array}{l}\text { H04M1/72 } \\
5 ; \\
\text { H04M1/02 }\end{array}$ & $\begin{array}{l}\text { Han } \\
\text { Dongfeng }\end{array}$ \\
\hline $\begin{array}{l}\text { A method of auto } \\
\text { alarm for } \\
\text { smartphone }\end{array}$ & $\begin{array}{l}\text { CN20121 } \\
0528675\end{array}$ & 2012.12 .10 & $\begin{array}{l}\text { H04W4/02 } \\
; \\
\text { H04M11/0 } \\
4\end{array}$ & $\begin{array}{l}\text { Zeng } \\
\text { yuanqing, } \\
\text { Liu } \\
\text { Jingquan }\end{array}$ \\
\hline $\begin{array}{l}\text { Car navigator, } \\
\text { smartphone based } \\
\text { navigation system } \\
\text { and their } \\
\text { authentication } \\
\text { method }\end{array}$ & $\begin{array}{l}\text { CN20131 } \\
0468118\end{array}$ & 2013.10 .10 & $\begin{array}{l}\text { G01C21/3 } \\
6 ; \\
\text { H04B5/02; } \\
\text { H04M11/0 } \\
0\end{array}$ & $\begin{array}{l}\text { Yi Runping, } \\
\text { Shi Qiang }\end{array}$ \\
\hline $\begin{array}{l}\text { Smartphone } \\
\text { navigation system }\end{array}$ & $\begin{array}{l}\text { CN20131 } \\
0505993\end{array}$ & 2013.10 .24 & $\begin{array}{l}\text { G01C21/3 } \\
4 ; \\
\text { H04M1/72 } \\
5\end{array}$ & $\begin{array}{l}\text { Wang } \\
\text { Yaobin }\end{array}$ \\
\hline $\begin{array}{l}\text { a smartphone and } \\
\text { a screen cover } \\
\text { with function of } \\
\text { wireless charge an }\end{array}$ & $\begin{array}{l}\text { CN20131 } \\
0569495\end{array}$ & 2013.11 .13 & H04M1/21 & $\begin{array}{l}\text { Du Jiamei, } \\
\text { Piao } \\
\text { Zheyou, } \\
\text { Leng } \\
\text { Hongxia, } \\
\text { Lin Aijinai }\end{array}$ \\
\hline
\end{tabular}




\begin{tabular}{|c|c|c|c|c|}
\hline $\begin{array}{l}\text { A messager based } \\
\text { video monitoring } \\
\text { method using } \\
\text { smartphone }\end{array}$ & $\begin{array}{l}\text { CN20131 } \\
0552045\end{array}$ & 2013.11 .08 & $\begin{array}{l}\text { H04N7/18; } \\
\text { H04L12/5 } \\
8 ; \\
\text { H04L29/0 } \\
6\end{array}$ & He Jianyi \\
\hline $\begin{array}{l}\text { A smartphone with } \\
\text { high safety }\end{array}$ & $\begin{array}{l}\text { CN20131 } \\
0526391\end{array}$ & 2013.10 .31 & $\begin{array}{l}\text { H04M1/02 } \\
; \\
\text { G06F21/3 } \\
\text { 1; } \\
\text { G06F21/6 } \\
0 ; \\
\text { G06F21/3 } \\
2\end{array}$ & $\begin{array}{l}\text { Li Yuwen, } \\
\text { Zhang } \\
\text { Xuejun, } \\
\text { Zhou yimin }\end{array}$ \\
\hline $\begin{array}{l}\text { A method of } \\
\text { mirroring from } \\
\text { smartphone to car } \\
\text { system }\end{array}$ & $\begin{array}{l}\text { CN20131 } \\
0590468\end{array}$ & 2013.11 .21 & $\begin{array}{l}\text { H04M1/72 } \\
5 ; \\
\text { H04L29/0 } \\
8\end{array}$ & $\begin{array}{l}\text { Qin Chunda, } \\
\text { Liu } \\
\text { Rongfeng, } \\
\text { Zheng } \\
\text { Jianping }\end{array}$ \\
\hline
\end{tabular}

The important patents generally involve "GPS", "touch/screen", "image", "video/audio", "phone case", "security/password" and "application", which are the key technology research fields of smartphone. The cross frequency matrix analysis gets the same conclusion.

\section{CONCLUSION}

This paper mainly introduces the application of multidimensional patent maps in the technology fields of the smartphone. By using patent maps this paper finds the important patents and discovers the treat of technology development in the field of smartphone. This paper retrieves patent data, selects patent keywords, draws keyword frequency matrix patent map, cross keyword frequency matrix patent map and relationship patent map, finds out the important patents and important topics of technology research for smartphone, reveals the future direction of technology development in the field of smartphone. "GPS/location", "touch/screen", "image", "video/audio", "phone case", "security/password" and "application" are the technology focuses and development trends of smartphones in the future.

\section{REFERENCES}

[1] Zhang Fan, Xiao Guohua, Zhang Xian. Patent map, the typical applications of $[\mathrm{J}]$. science and technology management research, 2008, (2): 190-194. (In Chinese)

[2] Wu Xinyin, Liu Ping. Preliminary study on patent map [J]. research and development management, 2003, 15 (5): 88-95. (In Chinese)

[3] Gu Zhenyu, Bian Zhixin, Lu Wei, Xiao Huwei. Application of patent map and empirical research $[\mathrm{J}]$. Journal of information, 2009, 28 (9): 21-28. (In Chinese)

[4] Chao-Chan $\mathrm{Wu}$, Hoang-Jyh Leu. Examining the trends of technological development in hydrogen energy using patent co-word map analysis[J]. 2014, (5):1-8.

[5] Koumi Ngoh S, Njomo D. An overview of hydrogen gas production from solar energy[J]. Renew Sustain Energy Rev, 2012, 16(9):6782-6792. 